\title{
A Three-Dimensional Unsteady CFD Model of Compressor Stability
}

Rodrick V. Chima

Glenn Research Center, Cleveland, Ohio 
Since its founding, NASA has been dedicated to the advancement of aeronautics and space science. The NASA Scientific and Technical Information (STI) Program Office plays a key part in helping NASA maintain this important role.

The NASA STI Program Office is operated by Langley Research Center, the Lead Center for NASA's scientific and technical information. The NASA STI Program Office provides access to the NASA STI Database, the largest collection of aeronautical and space science STI in the world. The Program Office is also NASA's institutional mechanism for disseminating the results of its research and development activities. These results are published by NASA in the NASA STI Report Series, which includes the following report types:

- $\quad$ TECHNICAL PUBLICATION. Reports of completed research or a major significant phase of research that present the results of NASA programs and include extensive data or theoretical analysis. Includes compilations of significant scientific and technical data and information deemed to be of continuing reference value. NASA's counterpart of peerreviewed formal professional papers but has less stringent limitations on manuscript length and extent of graphic presentations.

- TECHNICAL MEMORANDUM. Scientific and technical findings that are preliminary or of specialized interest, e.g., quick release reports, working papers, and bibliographies that contain minimal annotation. Does not contain extensive analysis.

- CONTRACTOR REPORT. Scientific and technical findings by NASA-sponsored contractors and grantees.
- CONFERENCE PUBLICATION. Collected papers from scientific and technical conferences, symposia, seminars, or other meetings sponsored or cosponsored by NASA.

- SPECIAL PUBLICATION. Scientific, technical, or historical information from NASA programs, projects, and missions, often concerned with subjects having substantial public interest.

- TECHNICAL TRANSLATION. Englishlanguage translations of foreign scientific and technical material pertinent to NASA's mission.

Specialized services that complement the STI Program Office's diverse offerings include creating custom thesauri, building customized databases, organizing and publishing research results ... even providing videos.

For more information about the NASA STI Program Office, see the following:

- Access the NASA STI Program Home Page at http://www.sti.nasa.gov

- E-mail your question via the Internet to help@sti.nasa.gov

- Fax your question to the NASA Access Help Desk at 301-621-0134

- Telephone the NASA Access Help Desk at 301-621-0390

- Write to:

NASA Access Help Desk

NASA Center for AeroSpace Information 7121 Standard Drive

Hanover, MD 21076 
NASA/TM-2006-214117

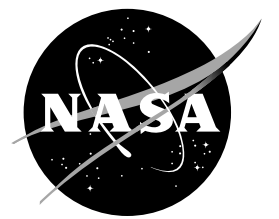

\section{A Three-Dimensional Unsteady CFD Model of Compressor Stability}

Rodrick V. Chima

Glenn Research Center, Cleveland, Ohio

Prepared for

Turbo Expo 2006

sponsored by the American Society of Mechanical Engineers

Barcelona, Spain, May 8-11, 2006

National Aeronautics and

Space Administration

Glenn Research Center 
This work was sponsored by the Fundamental Aeronautics Program at the NASA Glenn Research Center.

Available from

NASA Center for Aerospace Information 7121 Standard Drive

Hanover, MD 21076
National Technical Information Service 5285 Port Royal Road Springfield, VA 22100

Available electronically at http:/ /gltrs.grc.nasa.gov 


\title{
A THREE-DIMENSIONAL UNSTEADY CFD MODEL OF COMPRESSOR STABILITY
}

\author{
Rodrick V. Chima \\ National Aeronautics and Space Administration \\ Glenn Research Center \\ Cleveland, Ohio 44135
}

\begin{abstract}
A three-dimensional unsteady CFD code called CSTALL has been developed and used to investigate compressor stability. The code solved the Euler equations through the entire annulus and all blade rows. Blade row turning, losses, and deviation were modeled using body force terms which required input data at stations between blade rows. The input data was calculated using a separate Navier-Stokes turbomachinery analysis code run at one operating point near stall, and was scaled to other operating points using overall characteristic maps. No information about the stalled characteristic was used. CSTALL was run in a 2-D throughflow mode for very fast calculations of operating maps and estimation of stall points. Calculated pressure ratio characteristics for NASA stage 35 agreed well with experimental data, and results with inlet radial distortion showed the expected loss of range. CSTALL was also run in a 3-D mode to investigate inlet circumferential distortion. Calculated operating maps for stage 35 with 120 degree distortion screens showed a loss in range and pressure rise. Unsteady calculations showed rotating stall with two part-span stall cells. The paper describes the body force formulation in detail, examines the computed results, and concludes with observations about the code.
\end{abstract}

\section{NOMENCLATURE}

$b \quad$ blockage

$E, G, H \quad$ inviscid fluxes

e total energy

$F \quad$ body force for turning

$f \quad$ body force for loss

$h, p, T, s \quad$ enthalpy, pressure, temperature, entropy

$K \quad$ Centrifugal, Coriolis, and blockage source terms

$m \quad$ meridional directional

$\dot{m}_{c} \quad$ corrected mass flow

$q \quad$ vector of conserved variables

$t \quad$ time

V velocity

$x, \theta, r$
$u, v, w$
$\beta, \chi, \delta$
$\Delta$
$\xi$
$\rho$
$\tau$
$\Phi$
$\phi$
$\varphi_{\text {turn }}$
$\Omega$
$\omega$

\author{
cylindrical coordinates \\ cylindrical velocity components \\ relative flow, blade, and deviation angles \\ difference \\ streamwise grid direction \\ density \\ throughflow time scale \\ body force vector \\ body force scaling function \\ turning function for deviation \\ blade row angular velocity \\ loss coefficient \\ stagnation state \\ upstream, downstream \\ leading edge, trailing edge \\ turning, entropy, deviation, reference point \\ grid exit, downstream of throttle
}

\section{Subscripts \\ 0 \\ 1,2 \\ $L E, T E$ \\ $t, s, \delta, r e f$ \\ $e x, \infty$}

\section{Superscripts \\ $V^{\prime} \quad$ relative velocity \\ ss steady state}

\section{INTRODUCTION}

Compressor stall and surge can have catastrophic consequences in aircraft, yet prediction of these phenomena remains as one of the major unsolved problems in turbomachinery. Many models of stall that give some insight into the phenomena have been developed but few models are capable of predicting stall onset, except perhaps for full computational fluid dynamic (CFD) analysis of the entire compressor which is beyond the scope of this paper. Existing models range from analytic models of rotating stall or compression system stability to 2-D or 3-D CFD models of compression systems. All models require input of some information about compressor performance, 


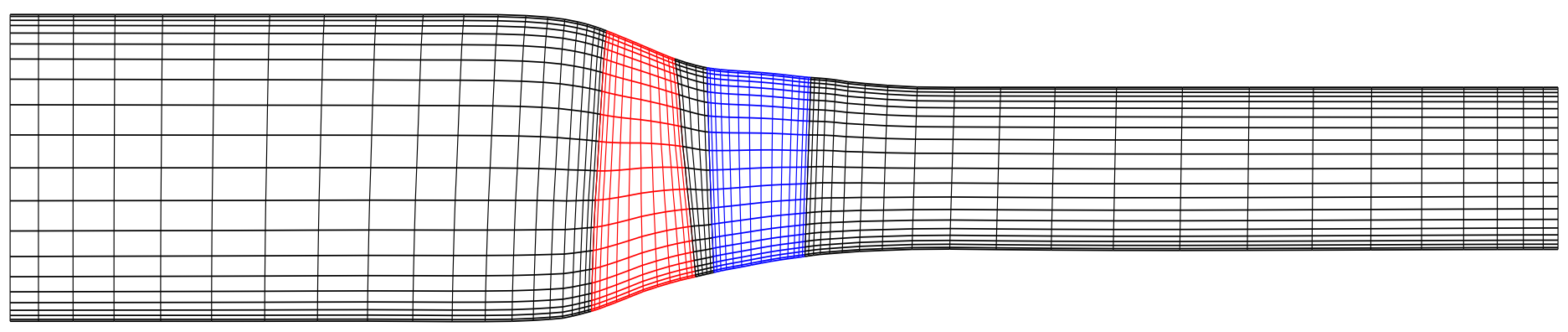

Figure 1 - Meridional grid used for NASA stage 35.

usually equivalent to axisymmetric pressure rise and loss characteristics for the machine over its entire operating range, including stall. This information can be difficult to obtain accurately. This paper describes a 3-D unsteady CFD model of compressor stability that uses a new method for obtaining information about compressor performance directly from steady CFD calculations performed separately. First some existing models and their input requirements will be described.

Pampreen [1] gives an excellent review of several analytic models of compressor stall. Early models predict the propagation velocity of stall cells. Later system stability models predict the behavior of a duct/ compressor/plenum/throttle system. These models usually assume that the axisymmetric static pressure rise characteristic of the compressor is known at all flow conditions, including stall.

Takata and Nagano [2] developed a nonlinear analysis of rotating stall that modeled incompressible flow through a 2-D isolated blade row with infinitesimal pitch but finite chord. The static pressure loss and exit flow angle were assumed to be known functions of the incidence angle, and changes in loss were assumed to lag in time behind changes in incidence. The numerical results predicted stall inception, stall cell growth, and stall cell propagation velocity. Several authors have extended these ideas to 2-D compressible flows using modern CFD methods. Longley [3] presented an unsteady 2-D model of compressor stability and tested the model for a hypothetical four-stage compressor. Demargne and Longley [4] applied the model to four real compressors. Lindau and Owen [5] applied a similar model to NASA compressor stage 35 . Both models used measured blade row characteristics extended over a large flow range as input, and used time-lag equations to update the body-force terms gradually.

Inviscid axisymmetric throughflow models have long been used to model steady flows in turbomachinery. These models represent the axisymmetric average flow on a meridional surface. Since the equations are averaged tangentially they cannot predict turning, and since they are inviscid they cannot predict losses. Body force terms are added to model these effects. Marble [6] derived a formulation for body forces required to produce given changes in swirl $\left(r v_{\theta}\right)$ and entropy along a streamline. Stewart [7] described an iterative formulation for body forces required to turn the flow to a given angle, and used that formulation in an axisymmetric model of a full engine. Both of these formulations were used in the present work and are described later.

By incorporating axisymmetric throughflow codes or ideas in unsteady CFD codes, several authors have developed codes for modeling circumferential distortion and stall. Throughflow codes usually incorporate extensive correlations for blade row turning and loss, and thus provide rough predictions of blade row performance at all operating points. The codes often require additional calibration for each new case. Escuret and Garnier [8] developed two unsteady codes for compressor instability. The first was a 2-D throughflow analysis that modeled stall and surge. The second was a 3-D stall model. Both codes were coupled to a SNECMA throughflow code to provide the blade row characteristics, and both used time-lag models to update the body-force terms. Hale, et al. [9] merged the HT0300 throughflow code and the 3-D NPARC code (now called WIND) to produce his TEACC code. That code was used to predict the effects of circumferential distortion on steady performance of an isolated rotor. Hale, et al. [10] used the same code to predict the performance of a 3-stage military fan coupled to an F-16 forebody and inlet.

Gong et al. [11] described a 3-D computational model for compressor instability. The model was applied to the GE low-speed (incompressible) research compressor and was used to simulate both modal and spike stall inception. Gong's dissertation [12] extended the model to compressible flows and used it to show the steady response of NASA stage 35 to inlet distortion. In this work the body forces were modeled using two constant force coefficients similar to lift and drag coefficients. Hsiao, et al. [13] incorporated the compressible model in the WIND Navier-Stokes code and used the code to analyze a nacelle/ fan/exit guide vane/nozzle configuration. Here the body forces were interpolated directly from 3-D Navier-Stokes solutions of the rotor and guide vane onto the entire throughflow grid, so the model was limited to one operating point.

In the present work a new CFD code called CSTALL was developed to investigate compressor stability. The code was used to solve the unsteady 3-D Euler equations through a compressor using a finitedifference scheme. The computational grid shown in Fig. 1 resolved the blade planform but was evenly spaced in the circumferential direction. The equations were treated as axisymmetric in blade passages (shown in color.) Marble's formulation for turning and loss forces was used for steady calculations, and Stewart's formulation for turning to a specified angle was used for unsteady calculations. Body force input data was calculated using a Navier-Stokes turbomachinery analysis code run at one operating point near stall, and was scaled to other operating points using normalized characteristic maps. No information about the stalled characteristic was used. The input data was easy to obtain and allowed the inviscid axisymmetric throughflow code to represent the blade rows with the same accuracy as the underlying Navier-Stokes calculations. CSTALL was used in a 2-D throughflow mode for fast calculations of operating maps and estimation of stall points, in a 3-D mode for calculations of circumferential distortion, 
and in a 3-D unsteady mode to investigate rotating stall in a compressor stage.

\section{GOVERNING EQUATIONS}

The governing equations are the Euler equations written in cylindrical coordinates $(x, \theta, r)$ in a stationary frame of reference.

$$
\frac{\partial q}{\partial t}+\frac{\partial E}{\partial x}+\frac{1}{r} \frac{\partial G}{\partial \theta}+\frac{\partial H}{\partial r}=K+\Phi
$$

where

$$
\begin{aligned}
& q=b r\left[\begin{array}{c}
\rho \\
\rho u \\
\rho v \\
\rho w \\
e
\end{array}\right] \quad K=\left[\begin{array}{c}
0 \\
r p \partial_{x} b \\
-b \rho v w \\
b\left(\rho v^{2}+p\right)+r p \partial_{r} b \\
0
\end{array}\right] \\
& E=b r\left[\begin{array}{c}
\rho u \\
\rho u^{2}+p \\
\rho u v \\
\rho u w \\
u(e+p)
\end{array}\right] \quad G=b r\left[\begin{array}{c}
\rho v \\
\rho u v \\
\rho v^{2}+p \\
\rho v w \\
v(e+p)
\end{array}\right] \quad H=b r\left[\begin{array}{c}
\rho w \\
\rho u w \\
\rho v w \\
\rho w^{2}+p \\
w(e+p)
\end{array}\right]
\end{aligned}
$$

The energy $e$ is given by $e=\rho\left(C_{v} T+\frac{1}{2} V^{2}\right)$ and the pressure $p$ is given by $p=(\gamma-1)\left(e-\frac{1}{2} \rho V^{2}\right)$, where $V^{2}=u^{2}+v^{2}+w^{2}$.

$\Phi$ is the total body force per unit mass and will be discussed in detail later. $K$ is a source term that includes the centrifugal and Coriolis forces, and derivatives of the blockage $b$, which is the fraction of the annulus open to the flow. To account for blade thickness, $b$ can be modeled as $b=\left|\theta_{s}-\theta_{p}\right| \frac{N}{2 \pi}$. To account for endwall blockage, $b$ can be varied by some function of axial distance.

\section{Axisymmetric Equations in Blade Passages}

The full 3-D Euler equations $(1-3)$ are solved in the annular ducts outside of blade passages. Within blade passages there should be no communication with neighboring passages, but the uniform computational grid used here does not resolve the solid blade shapes. Instead it is assumed that blades are infinitely thin and that the flow is axisymmetric on each meridional grid surface. The blockage term $b$ described above is used to account for variation of the throughflow velocity due to finite blade thickness.

Stator passages are modeled as axisymmetric in the absolute frame of reference and the $\theta$-derivatives can be dropped immediately:

$$
\frac{1}{r} \frac{\partial G}{\partial \theta}=0 \text { in stator passages. }
$$

Rotor passages are modeled as axisymmetric in the relative frame of reference. Equations ( 1 - 2) are transformed to the relative frame, all $\theta$-derivatives are set to zero, then the equations are transformed back to the absolute frame. The result is that

$$
\frac{1}{r} \frac{\partial G}{\partial \theta} \rightarrow \Omega \frac{\partial q}{\partial \theta} \text { in rotor passages, }
$$

where $\Omega$ is the blade row rotational speed.

\section{BODY FORCES}

Ducts are modeled using the 3-D Euler equations with all body forces $\Phi=0$. Blade passages are modeled using the axisymmetric Euler equations which give no information about turning or loss. That information is specified using the body force term $\Phi$. The formulation used for $\Phi$ is based on the formulation developed by Marble [6] and outlined below.

The body force array used in (1) may be written as

$$
\Phi=\operatorname{br}\left[0, \Phi_{x}, \Phi_{\theta}, \Phi_{r}, r \Omega \Phi_{\theta}\right]^{T} \quad \text { in blade passages. }
$$

The term $r \Omega \Phi_{\theta}$ used in the energy equation represents the work done by a rotor.

The total force vector $\vec{\Phi}$ can be written as $\vec{\Phi}=\vec{F}+\vec{f}$, where $\vec{F}$ is a turning (or lift) force normal to the relative velocity $\vec{V}^{\prime}$,

$$
\begin{gathered}
\vec{F} \cdot \overrightarrow{V^{\prime}}=0 \\
u F_{x}+v^{\prime} F_{\theta}+w F_{r}=0
\end{gathered}
$$

and $\vec{f}$ is a loss (or drag) force parallel but opposed to $\vec{V}^{\prime}$

$$
\begin{gathered}
\vec{f} \| \overrightarrow{V^{\prime}} \\
\left(f_{x}, f_{\theta}, f_{r}\right)=-|\vec{f}| \frac{\left(u, v^{\prime}, w\right)}{\left|\overrightarrow{V^{\prime}}\right|}
\end{gathered}
$$

where $v^{\prime}=v-r \Omega$ is the relative tangential velocity component.

The components of these forces can be found by starting with the steady, axisymmetric Euler equations in non-conservative form. The equations can be written along a meridional streamline $m$ using the following transformations:

$$
\begin{aligned}
d m^{2} & =d x^{2}+d r^{2} \\
v_{m}^{2} & =u^{2}+w^{2} \\
v_{m} \partial_{m} & =u \partial_{x}+w \partial_{r}
\end{aligned}
$$

The momentum equations become simply

$$
\begin{array}{ll}
\mathrm{x}: & \rho v_{m} \partial_{m} u+\partial_{x} p=\Phi_{x} \\
\theta: & \rho v_{m} \partial_{m}(r v)=r \Phi_{\theta} \\
\mathrm{r}: & \rho v_{m} \partial_{m} w+\partial_{r} p=\frac{\rho v^{2}}{r}+\Phi_{r}
\end{array}
$$


The $\theta$-momentum equation immediately gives the total tangential force,

$$
\Phi_{\theta}=F_{\theta}+f_{\theta}=\rho \frac{v_{m}}{r} \frac{\partial(r v)}{\partial m}
$$

showing that the change of angular momentum along a streamline is proportional to the total applied tangential force.

Loss forces are derived from the canonical equation of state, $T d s=d h-d p / \rho$. This equation is applied along a streamline and the pressure gradient is eliminated using the momentum equations, giving:

$$
\begin{gathered}
v_{m} \partial_{m} h_{0}-r \Omega \Phi_{\theta}=T v_{m} \partial_{m} s \\
+u\left(F_{x}+f_{x}\right)+v^{\prime}\left(F_{\theta}+f_{\theta}\right)+w\left(F_{r}+f_{r}\right)
\end{gathered}
$$

where $h_{0}$ is the total enthalpy. Equation (7) can be used to eliminate three terms on the right hand side, leaving

$$
v_{m} \partial_{m} h_{0}-r \Omega \Phi_{\theta}=T v_{m} \partial_{m} s+\left(u f_{x}+v^{\prime} f_{\theta}+w f_{r}\right)
$$

In the absence of losses the right side of (13) equals zero since the entropy gradient $\partial_{m} s$ and the loss forces $f_{i}$ are both zero. The terms remaining on the left side of (13) give:

$$
v_{m} \frac{\partial h_{0}}{\partial m}=r \Omega \Phi_{\theta}=r \Omega\left(F_{\theta}+f_{\theta}\right)
$$

Equations (11) and (14) can be combined to give the differential form of the Euler turbine equation:

$$
\frac{\partial h_{0}}{\partial m}=\Omega \frac{\partial(r v)}{\partial m}
$$

which will be used later.

Equation (14) says that the rate of increase of total enthalpy along a streamline equals the rate at which torque does work on the system. This is a general application of the first law of thermodynamics and is true whether losses are present or not. Thus it follows that the entropy variation along a streamline can found from the right side of (13):

$$
T v_{m} \partial_{m} s=-\left(u f_{x}+v^{\prime} f_{\theta}+w f_{r}\right)=-\vec{f} \cdot \overrightarrow{V^{\prime}}
$$

Solving for the magnitude of the loss force $|f|$,

$$
|f|=T \frac{v_{m}}{\mid \overrightarrow{V^{\prime}}} \mid \frac{\partial s}{\partial m}
$$

At this point $f_{x}, f_{\theta}, f_{r}$, and $F_{\theta}=\Phi_{\theta}-f_{\theta}$ are all known. The meridional turning force $F_{m}$ is found using equation $(7$,$) then$ $F_{x}$ and $F_{r}$ are found by assuming that $F_{m}$ is tangent to the streamwise $(\xi)$ grid lines which follow the hub and casing.

$$
F_{m}=-F_{\theta}\left(\frac{v_{\theta}^{\prime}}{v_{m}}\right) \quad F_{x}=\frac{x_{\xi}}{\sqrt{x_{\xi}^{2}+r_{\xi}^{2}}} F_{m} \quad F_{r}=\frac{r_{\xi}}{\sqrt{x_{\xi}^{2}+r_{\xi}^{2}}} F_{m}
$$

\section{Body Force Required to Turn to a Specified Angle}

It is often desirable to specify the relative flow angle $\beta=\chi+\delta$ within the blade row, where $\chi$ is the blade angle and $\delta$ is the deviation. There does not seem to be a way to specify the turning force $\Phi_{\theta}$ explicitly in terms of $\beta$; however, an iterative scheme similar to a scheme described by Stewart [7] can be used. The angles are shown in Fig. 2 and the relative velocity $V^{\prime}$ is shown misaligned with the desired flow angle $\beta+\chi$. A turning force is defined to be proportional to the difference between the desired and actual tangential velocity components,

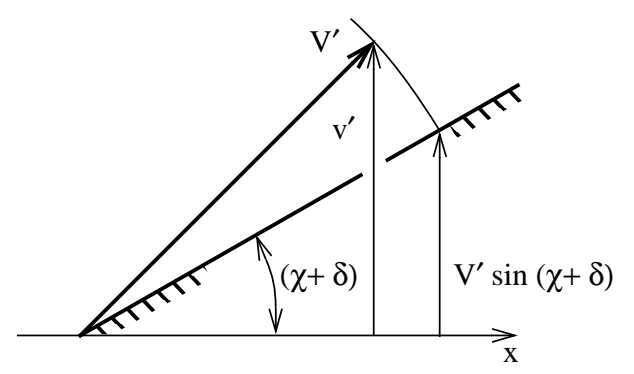

Figure 2 - Nomenclature used for deviation model.

$$
\begin{gathered}
F_{\theta}^{n+1}=F_{\theta}^{n}+\left(\frac{V^{\prime} \sin (\chi+\delta)-v^{\prime}}{\Delta t}\right) \varphi_{t u r n} \\
\varphi_{t u r n}=\sqrt{\frac{m-m_{l e}}{m_{t e}-m_{l e}}}
\end{gathered}
$$

When the flow turns to the desired angle $F_{\theta}^{n+1}=F_{\theta}^{n}$ and the iteration is converged.

$\varphi_{\text {turn }}$ is a turning function that varies the body force from zero at the leading edge to maximum at the trailing edge. Other turning functions based on the local blade angle were investigated, but they often resulted in non-physical supersonic throughflow velocities at flow rates below the experimental rotor choking flow.

\section{Body Force Unknowns}

Either equation (11) or (19) can be used to find the magnitude of the total tangential turning force. For convenience equation (11) will be referred to as the turning model and equation (19) will be referred to as the deviation model. Equation (13) gives the magnitude of the loss force.

The term $\partial(r v) / \partial m$ in (11) cannot be calculated using the axisymmetric equations, and the terms $\partial s / \partial m$ in (17) and $\delta$ in (19) cannot be calculated from the Euler equations. Here these terms have been modeled using results from steady Navier-Stokes calculations done previously using the author's CFD code SWIFT, see Chima [14, 15.] However, these terms could also be calculated from experimental data or design intent using the same formulation. The terms were approximated as a combination of spanwise reference profiles evaluated 

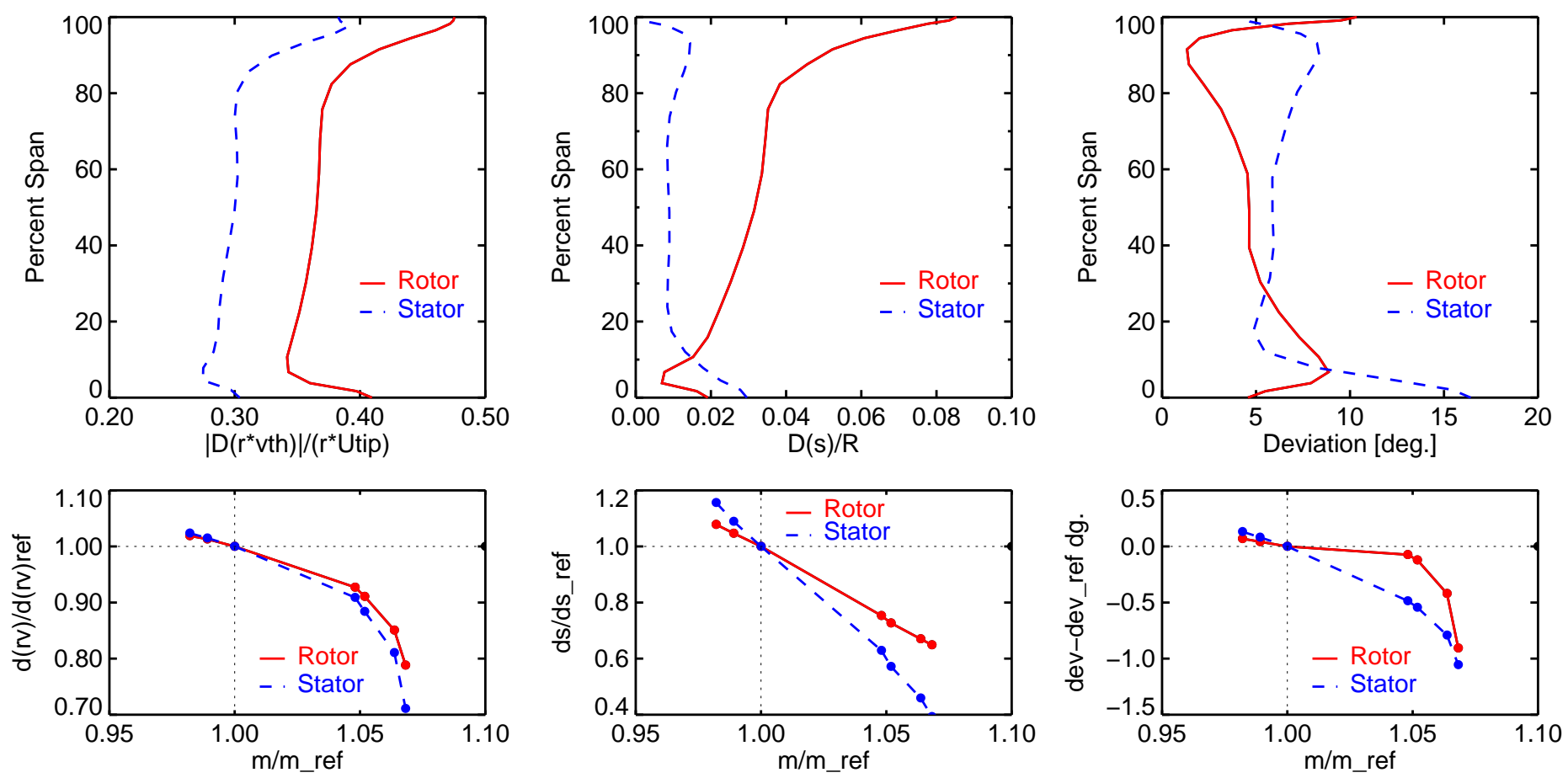

Figure 3 - Top: Spanwise profiles of $\Delta(r v), \Delta s / R$, and deviation computed with SWIFT.

Bottom: Maps of 1-D variation of $\Delta(r v), \Delta s / R$, and deviation with corrected flow computed with SWIFT.

upstream and downstream of each blade row at a single reference flow near stall, and a scaling function that varied with corrected flow.

$$
\begin{gathered}
\left.\left.\frac{\partial(r v)}{\partial m} \approx \frac{\Delta(r v)}{\Delta m}\right|_{r e f} \phi_{t}\left(\dot{m}_{c}\right) \quad \frac{\partial s}{\partial m} \approx \frac{\Delta s}{\Delta m}\right|_{r e f} \phi_{s}\left(\dot{m}_{c}\right) \\
\delta=\delta_{r e f}+\phi_{\delta}\left(\dot{m}_{c}\right)
\end{gathered}
$$

In (20), the terms labeled ref are the spanwise reference profiles. They were evaluated from a single SWIFT solution and stored for each blade at each spanwise location. The gradient terms $\left(\Delta^{\prime} s\right)$ were evaluated along streamwise grid lines, although technically they should be evaluated along streamlines. They were differenced between stations upstream and downstream of a blade. Since $r v$ and $s$ are convected along streamlines, the exact axial location of these stations is unimportant. Since the gradients were modeled as constants, the turning and loss vary linearly through the blade row. The deviation $\delta_{r e f}$ was evaluated at blade trailing edges.

For a rotor the term $\Delta(r v) / \Delta m$ can be calculated from Euler's turbine equation (15.) For a stator it must be input directly.

The entropy gradient was evaluated using the canonical equation of state written in terms of total conditions and integrated across a blade row:

$$
\frac{\Delta s}{R}=\frac{\gamma}{\gamma-1} \ln \left(\frac{T_{02}}{T_{01}}\right)-\ln \left(\frac{P_{02}}{P_{01}}\right)
$$

For a stator the temperature ratio equals one, and it can be shown that $\Delta s / R \approx \omega$, the total pressure loss coefficient.

The input reference profiles are shown at the top of Fig. 3 (the SWIFT calculations are discussed later.) The turning profiles show that the rotor adds swirl to the flow with overturning at the endwalls, and that the stator removes most of the swirl. The entropy rise profiles show that the rotor is especially lossy at the tip, and that the cantilevered stator is lossy at the hub. The deviation profiles are fairly uniform except at the endwalls. Since these profiles were evaluated by averaging a 3-D Navier-Stokes solution, they inherently include losses, blockage, and over- or under-turning due to shock-boundary layer interaction, tip clearance flows, and secondary flows, all of which are important for modeling stall in tip-critical blades.

In (20), the terms $\phi\left(\dot{m}_{c}\right)$ are normalized scaling functions used to scale the reference profiles to other flow rates. They are defined as:

$$
\begin{gathered}
\phi_{t}\left(\dot{m}_{c}\right)=\frac{\overline{\Delta(r v)}\left(\dot{m}_{c}\right)}{\overline{\Delta(r v)}\left(\dot{m}_{c}\right)_{r e f}} \quad \phi_{s}\left(\dot{m}_{c}\right)=\frac{\overline{\Delta s}\left(\dot{m}_{c}\right)}{\overline{\Delta s}\left(\dot{m}_{c}\right)_{r e f}} \\
\phi_{\delta}\left(\dot{m}_{c}\right)=\left[\delta\left(\dot{m}_{c}\right)-\delta\left(\dot{m}_{c}\right)_{\text {ref }}\right]_{\text {midspan }}
\end{gathered}
$$

The overbar denotes a spanwise average, i.e., $\overline{\Delta(r v)} \approx \bar{r}_{2} \bar{v}_{2}-\bar{r}_{1} \bar{v}_{1}$ and $\overline{\Delta s}=\bar{s}_{2}-\bar{s}_{1}$. The deviation scaling function was evaluated at midspan since the spanwise average deviation is poorly defined. 
The scaling functions vary with $\dot{m}_{c}$, the corrected mass flow at the blade leading edges. They are normalized such that they have no effect at the reference flow $\left(\dot{m}_{c}\right)_{\text {ref }}$. They were evaluated using SWIFT calculations of the stage speed line but could also be evaluated using experimental data or design intent. The functions were input as short tables for each blade row and interpolated linearly as needed. The functions were extrapolated linearly outside the range of the input data, but the mass flow was restricted to be less than the calculated choking value and greater than some stall cutoff. When the code was used to determine the stall point the cutoff was set very small. When it was used to calculate behavior in stall the cutoff was set to about 80 percent of the computed stall flow. The input scaling functions are shown at the bottom of Fig. 3. The turning, entropy rise, and deviation all increase as flow rate decreases, as expected. Surprisingly, the entropy rise is linear with flow rate for both blade rows.

For 3-D flows body forces were calculated independently on each meridional grid plane. References profiles were the same for all planes but scaling functions were determined for each plane based on the inlet corrected flow per unit area for that plane. In that way body forces could respond to circumferential variations in upstream conditions. Note that body forces are also functions of the local velocity and thermodynamic properties that are computed as part of the solution.

\section{Body Force Lag Model}

The body force terms described above are functions of the corrected mass flow calculated at blade leading edges and respond instantaneously everywhere to changes in that flow. In reality the blade forces respond gradually to changes in flow or incidence. Time-lag models are commonly used to simulate this finite response rate, (see Longley [3] or Lindau, et al. [5].) The following time-lag model was used in the present work:

$$
\tau \frac{\partial F}{\partial t}=\left(F^{s s}-F\right)
$$

where $\tau$ is a time scale associated with the blade response, typically the throughflow time, $\mathrm{F}$ is $F_{\theta}$ or $|f|$ (the lag model is applied to both,) and $F^{s s}$ is the steady state value of the force. Computationally the model is applied using,

$$
F^{n+1}=(1-r) F^{n}+r F^{s s} .
$$

where $r=\Delta t / \tau$ is an under relaxation factor. For steady calculations $r=1$. For the unsteady calculations shown later the throughflow time is about $100 \Delta t$, so that $r=0.01$.

\section{NUMERICAL MODEL}

The Euler equations (1-3) were transformed to body-fitted coordinates using finite-difference techniques described in Tweedt, et al. [16.] Since the computational grid was uniform in the tangential direction, $(\Delta \theta=$ constant $)$, the grid and metrics only required 2-D storage. The equations were discretized with either a central-difference scheme or the $\mathrm{AUSM}^{+}$upwind scheme described by Chima, et al. [15.] The equations were solved using an explicit Runge-Kutta scheme. For steady flows a two-stage scheme with spatially-varying time step and implicit residual smoothing was used to accelerate convergence. For unsteady flows a second-order four-stage scheme with constant time step was used.

\section{Boundary Conditions}

At the inlet the upstream-running Riemann invariant was extrapolated from the interior, and $P_{0}, T_{0}$, and $v$ were specified. In all cases $T_{0}$ was constant and $v=0$. The inlet $P_{0}$ profile reflected the turbulent inlet boundary layer profiles and resulting blockage used in SWIFT, but it was extrapolated to the wall on the coarser Euler grids used in CSTALL to avoid problems with zero velocity at the wall. For radial and circumferential distortion the inlet $P_{0}$ profile was modified locally as described later.

At the exit, $u, v$, and $w$ were extrapolated from the interior and $\rho$ was set isentropically. The pressure was set using the radial equilibrium equation and a throttle model,

$$
p_{e x}=p_{\infty}+\frac{K_{t}}{2} \rho V_{e x}^{2}+\int_{r_{h u b}}^{r} \frac{\rho v^{2}}{r} d r
$$

Here $K_{t}$ is a dimensionless throttle coefficient discussed later and $p_{\infty}$ is the static pressure downstream of the throttle.

\section{RESULTS}

\section{NASA Stage 35}

NASA stage 35 is a transonic inlet stage for a core compressor and was used here as a test case. The stage has a design pressure ratio of 1.82 at a mass flow of $20.19 \mathrm{~kg} / \mathrm{sec}$ and a rotor tip speed of $455 \mathrm{~m} / \mathrm{sec}$. The rotor has 36 multiple-circular-arc (MCA) blades with a maximum radius of $9.94 \mathrm{~cm}$ and a tip clearance of $\sim 0.2$ percent of the span. The cantilevered stator has 46 MCA blades with a hub clearance of $\sim 0.5$ percent span. The endwall clearances were much smaller than the grid spacing used in Fig. 1, but the effects of the clearances were captured by the reference profiles used in Fig. 3. Stage 35 was originally designed and tested at NASA Glenn Research Center by Reid and Moore [17.] Radial distributions of static and total pressure, total temperature, and flow angle were measured at axial stations located one rotor axial chord upstream of the rotor and 2.43 chords downstream of the stator. All calculations reported here were made at 100 percent design speed to allow comparison with this data.

\section{SWIFT - Navier-Stokes Analysis}

The SWIFT code is a multiblock Navier-Stokes analysis code for turbomachinery blade rows described by Chima, et al. $[14,15$.$] The$ code solves the Navier-Stokes equations on body-fitted grids using an explicit finite-difference scheme. It includes viscous terms in the blade-to-blade and hub-to-tip directions, but neglects them in the streamwise direction using the thin-layer approximation. The Baldwin-Lomax turbulence model was used for the present work. Multi blade row calculations were made using a steady mixing plane approach that transfers characteristic variables across the interface between blade rows. 
A central difference scheme was used. Artificial dissipation and Eigenvalue scaling were used to capture shocks and to control point decoupling. An explicit, four-stage Runge-Kutta scheme was used to solve the flow equations. Calculations were run at a Courant number of 5.6 using a spatially-varying time step and implicit residual smoothing to accelerate convergence to a steady state.

Calculations for stage 35 were run using a grid with five blocks: an H-block upstream, C-blocks around the rotor and stator, and O-blocks for the rotor tip clearance and stator hub clearance. Tip clearance grids had 9-11 points across the gap. The full grid had about 1.13 million points. The calculations were run several years ago on the Cray C-90 at NASA Ames Research Center, on 6-8 processors. Cases near choke were run 3,000 iterations, which took about 1.1 hours wall clock time. Cases near stall were often run 3-4 times as long to ensure convergence.

\section{CSTALL - Euler Analysis}

CSTALL calculations were run on the axisymmetric grid shown in Fig. 1 . The grid had 147 points axially and 21 points spanwise, for a total of 3,087 points. Steady 2-D cases were run with a 2-stage RungeKutta scheme on an SGI Octane2 with two processors. Cases near choke were converged to machine zero in 3,000 iterations, which took about 30 seconds. Cases near stall were often run 15-20,000 iterations to ensure convergence.

3 -D cases were run with 90 points evenly spaced in the circumferential direction, for a total of 278,830 points. Steady cases near choke took about an hour. Unsteady 3-D cases were run with a 4-stage Runge-Kutta scheme with a constant time step and no residual smoothing. The time step was chosen to give a maximum Courant number of about 2.5. One rotor revolution required 2,500 time steps, which took about 40 minutes on the SGI. A dual time stepping scheme could be used to reduce CPU time for unsteady cases but was not used here.

\section{Predicted Performance}

Figure 4 compares static-to-total pressure ratio characteristics for stage 35 as measured by Reid and Moore [17] with characteristics computed by three different methods. The experimental data (solid black circles) show a non-zero slope near the stall point of $18.2 \mathrm{~kg} /$ sec. The characteristic computed with the SWIFT code (plus signs) matches the experimental data closely but predicts stall at a higher flow of $19.23 \mathrm{~kg} / \mathrm{sec}$. The reason for the discrepancy in predicted stall point is unknown, but was found to be unaffected by changes in grid resolution, differencing scheme, and turbulence model. CSTALL solutions computed with the turning model (red squares) and the deviation model (black triangles) agree closely with each other and with the SWIFT solution up to the stall point. However, the CSTALL results predict stall at slightly lower flow than the experiment and a much lower flow than SWIFT.

Since stall models typically require input of an axisymmetric characteristic that mimics stall, e.g. Gong [12,] it was not obvious in advance whether the CSTALL formulation could even predict stall. Subsequent results will show the mechanism responsible for stall in the calculations. For now, note that the CSTALL solutions were computed using the scaling functions computed with SWIFT (Fig. 3, which were extrapolated linearly to the left of the predicted stall point

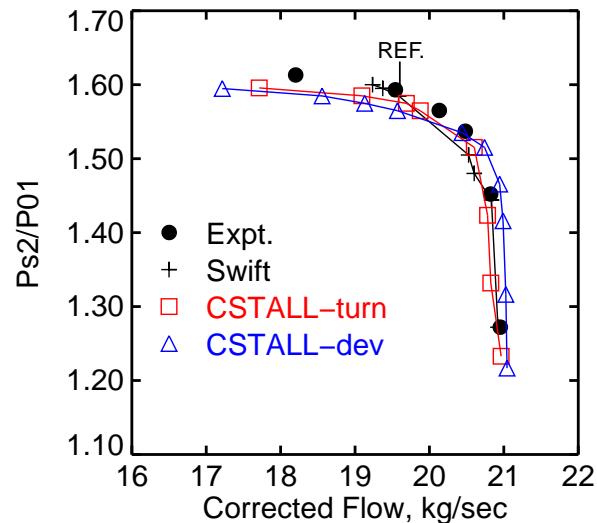

Figure 4 - Experimental and computed characteristics of static-to-total pressure ratio for stage 35 .

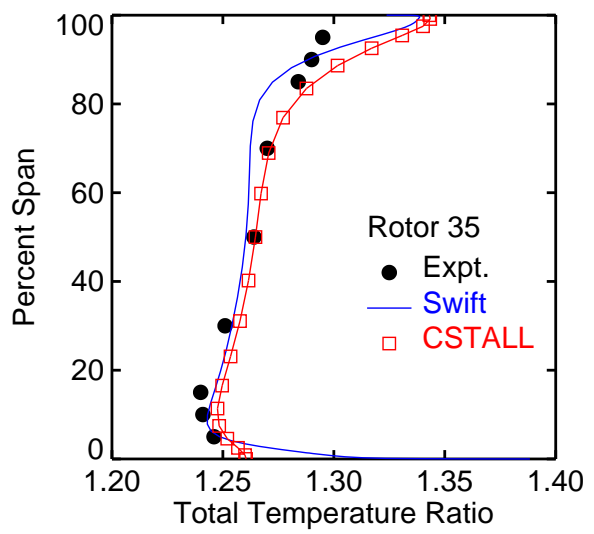

Figure 5 - Spanwise distributions of experimental and computed total temperature ratio downstream of rotor 35 .

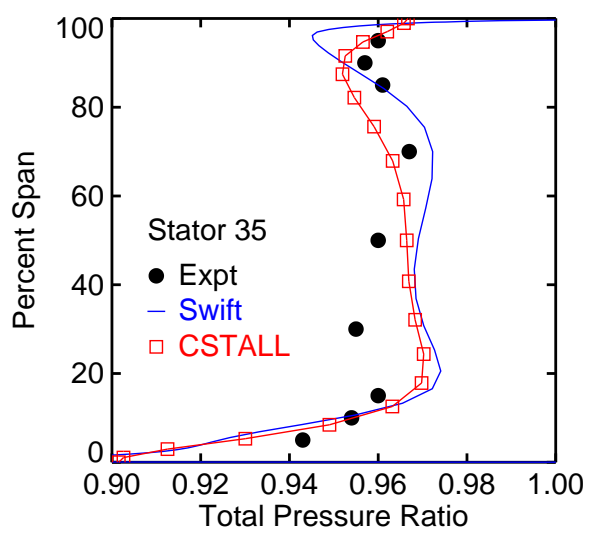

Figure 6 - Spanwise distributions of experimental and computed total pressure ratio downstream of stator 35 .

as necessary. It was found that the predicted stall point depended strongly on the slopes of the scaling functions at the stall point. Small changes in the slopes could be used to make the predicted stall points match, but here the slopes were left as predicted by SWIFT. 
In general the turning and deviation models gave similar results at stable operating points. However, at stalled operating points the turning model gave non-physical swings in flow angles while the deviation model held the flow angle close to the blade angle even when the flow reversed direction. Hence the remainder of this paper will only show results from the turning model at stable points and from the deviation model at stalled points.

CSTALL solutions were computed using reference profiles from the SWIFT solution at $19.74 \mathrm{~kg} / \mathrm{sec}$ (labeled REF. on Fig. 4) and should agree with SWIFT at that flow rate. Spanwise profiles of total temperature ratio downstream of the rotor are compared in Fig. 5. The SWIFT predictions (black line) agree closely with experimental data (black circles) except near the tip, where a higher temperature ratio was predicted. The CSTALL predictions (red squares) agree reasonably well with the SWIFT predictions, showing that the body forces for turning are behaving correctly. Spanwise profiles of total pressure ratio across the stator are compared in Fig. 6 . The SWIFT predictions (black line) are about a point higher than the data (black circles,) but do show the large loss due to the stator hub clearance. The CSTALL predictions (red squares) agree reasonably well with the SWIFT predictions, showing that the body forces for loss are also behaving correctly. Minor differences between SWIFT and CSTALL in Figs. 5 and 6 could be due to a number of modelling simplifications used in CSTALL, such as estimation of the body forces using data along grid lines rather than streamlines, neglect of losses in ducts, etc.

\section{Stall Mechanism}

CSTALL calculations of a speed line (Fig. 4) behave like most Navier-Stokes calculations, with fast convergence near choke and slow convergence near stall. When the exit pressure is raised above the stall point the mass flow drops rapidly and large regions of reverse flow develop. Investigation of the flow field at the stall point suggests the mechanism by which the calculations predict stall. Figure 7 shows predicted axial velocity contours within the stage at the last stable operating point of Fig. 4. The plot shows a region of low axial velocity on the casing from the rotor trailing edge to the stator leading edge. This low-speed region is directly related to the high entropy rise across the rotor at the tip (Fig. 3, top center.) Figure 8 plots the axial velocity on the casing vs. axial distance. The upper plot is for the next to the last stable operating point on Fig. 4 and the lower plot is for the stall point. It is apparent that the axial velocity at the casing goes to zero quickly as the flow approaches stall, and that the stage stalls when the velocity reaches zero.

\section{Effect of Throttle Boundary Condition}

The static-to-total pressure ratio characteristics shown in Fig. 4 were calculated using radial equilibrium at the exit (eq. 25) but not the throttle model, i.e., $K_{t}=0$. The throttle coefficient for the stage 35 experiment was estimated to be $K_{t} \approx 1.314$ using SWIFT results at the grid exit and assuming that the throttle exhausted back to the ambient. Another characteristic was calculated by holding $K_{t}=1.314$ constant and varying $p_{\infty}$. The throttle characteristic at the stall point (black line) and the compressor characteristics predicted with and without the throttle boundary condition are shown in Fig. 9. The throttle boundary condition reduced the predicted stall

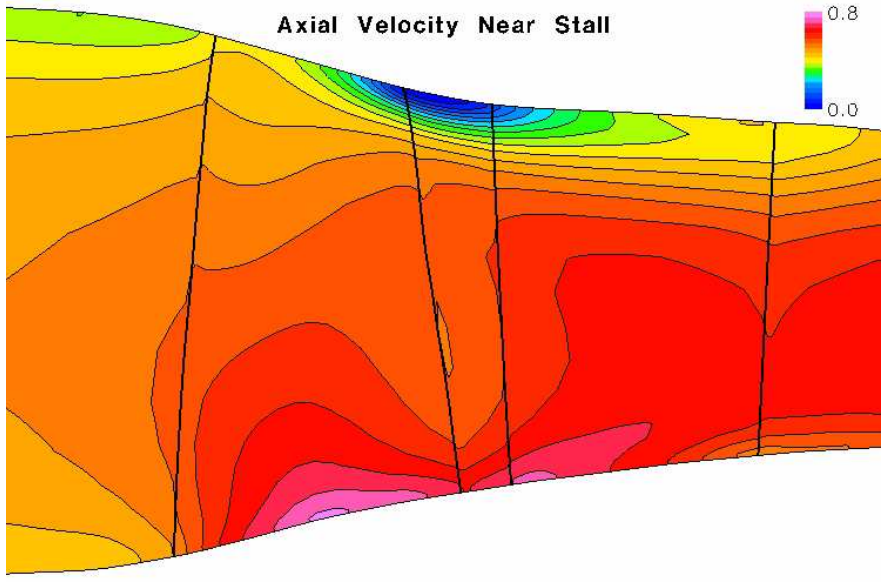

Figure $7-$ Axial velocity component contours at stall.

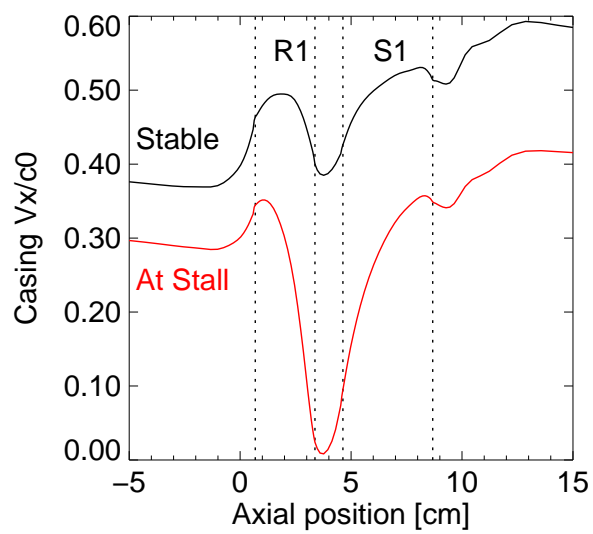

Figure 8 - Axial velocity along the casing of stage 35 at flow rates before stall (stable) and at stall.

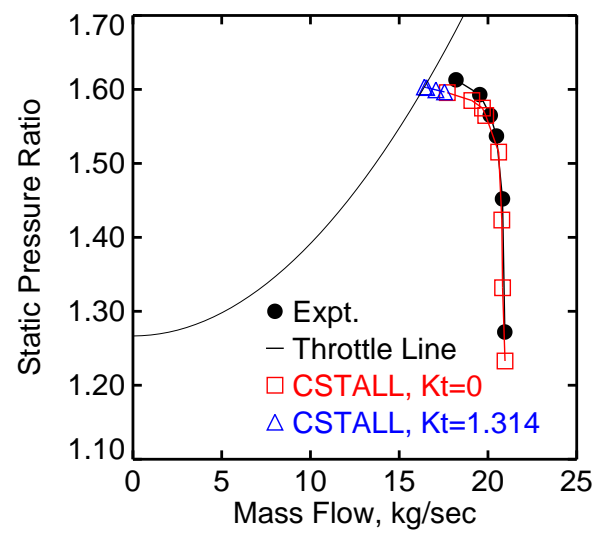

Figure 9 - Effect of throttle exit boundary condition on the stall point.

point from $17.1 \mathrm{~kg} / \mathrm{sec}$ (red squares) to $16.4 \mathrm{~kg} / \mathrm{sec}$ (blue triangles.) The slope of the static-to-total pressure ratio characteristics remained negative over the entire flow range. Since the CSTALL results predict a stall point slightly lower than the experiment even with $K_{t}=0$, the throttle boundary condition was not used for subsequent calculations. 


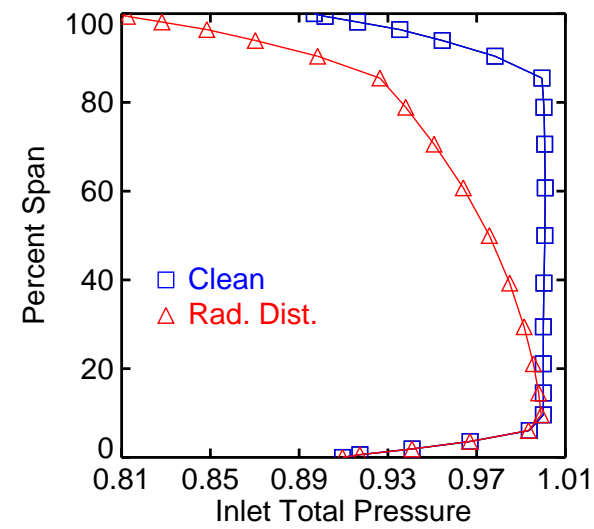

Figure 10 - Inlet total pressure profiles specified for stage 35.

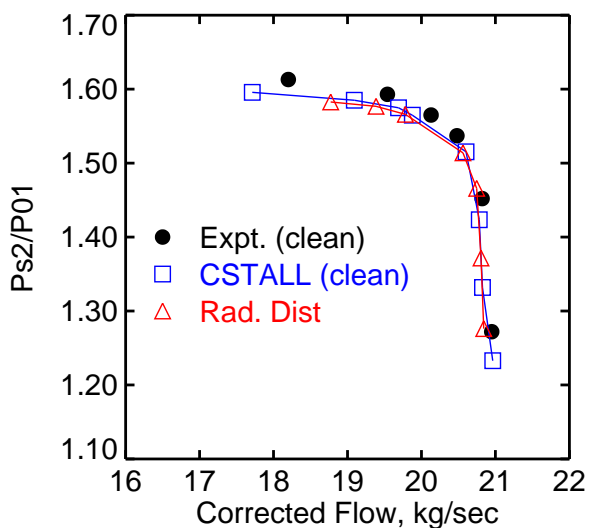

Figure 11 - Experimental and computed characteristics of static-to-total pressure ratio with and without radial distortion.

\section{Radial Distortion}

CSTALL requires input for a few operating points of a compressor. This input can be derived from steady Navier-Stokes calculations of periodic blade rows with clean inflow. Once this input is available CSTALL can be used to investigate the effects of inlet distortion on the performance of the compressor without the need for further Navier-Stokes computations.

Radial distortion can have a big impact on compressor stability but it is easy to model with CSTALL. It was modeled by running CSTALL in a 2-D mode with the specified inlet total pressure profile modified as shown in Fig. 10. Figure 11 compares the predicted staticto-total pressure ratio characteristic with radial distortion to the computed and measured characteristics with clean flow shown previously. Radial distortion greatly reduces the actual mass flow and exit static pressure from their clean flow values, but the normalized characteristic of static-to-total pressure ratio versus corrected mass flow (red triangles) collapses onto the clean flow characteristic (blue squares.) The main effect of radial distortion is to increase the predicted stall flow from $17.1 \mathrm{~kg} / \mathrm{sec}$. to $18.8 \mathrm{~kg} / \mathrm{sec}$.

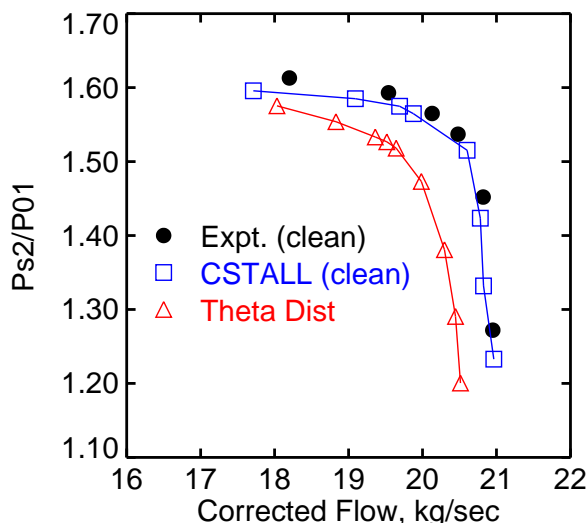

Figure 12 - Experimental and computed characteristics of static-to-total pressure ratio for stage 35 with and without circumferential distortion.

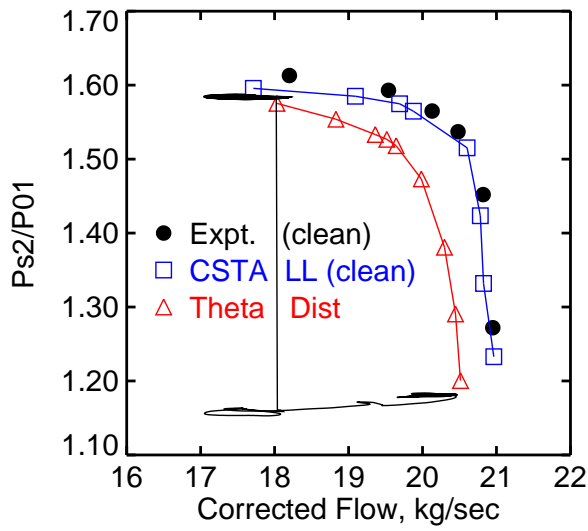

Figure 13 - Computed characteristic of static-to-total pressure ratio for stage 35 with circumferential distortion during stall and stall recovery.

\section{Circumferential Distortion}

Circumferential distortion is a 3-D problem that requires analysis of the entire annulus. This is costly to compute with a Navier-Stokes code but easy to compute with CSTALL because CSTALL uses an Euler formulation and a much coarser grid. Circumferential distortion was modeled by running CSTALL in a 3-D mode with the inlet total pressure profile reduced by 13 percent over a 120 degree segment of the inlet boundary. Figure 12 compares the predicted static-to-total pressure ratio characteristic with circumferential distortion to the computed and measured characteristics with clean flow shown previously. Like radial distortion, circumferential distortion reduces the actual mass flow and exit static pressure from their clean flow values. Unlike radial distortion, the normalized static-to-total pressure ratio versus corrected mass flow characteristic does not collapse onto the clean characteristic, but becomes lower everywhere.

At operating points near stall it was noted that many circumferential locations in the distorted region were well below the stall point on the body force calibration curves (Fig. 3.) In this case a parallel compressor model would predict that the stage would be stalled, but the present model predicts stable operation. 

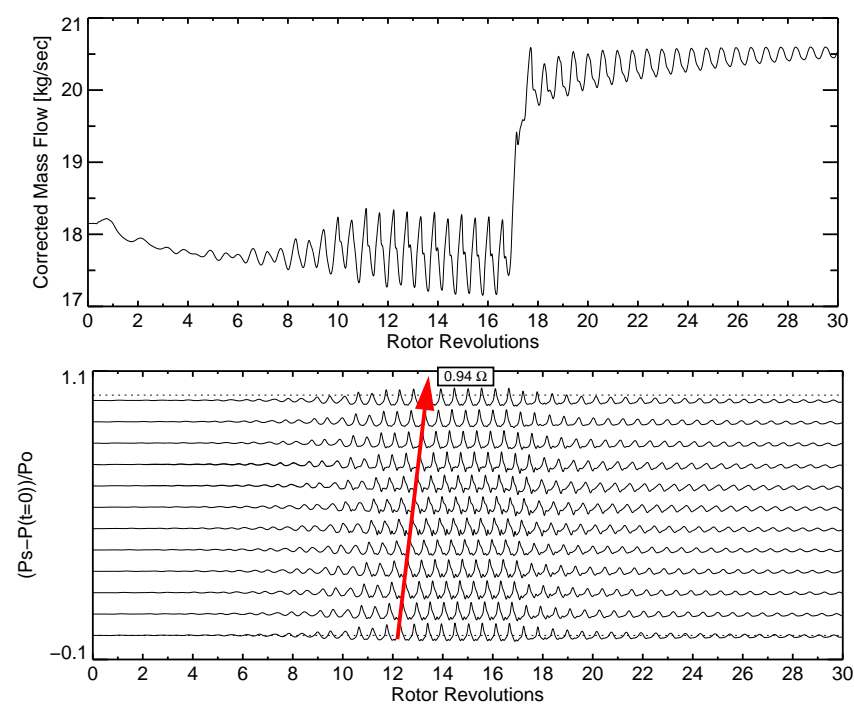

Figure 14 - Top: Inlet corrected mass flow for stage 35 during stall and stall recovery.

Bottom: Casing static pressures at 12 circumferential locations at the leading edge of rotor 35 during stall and stall recovery.

The calculations were pushed from the last stable operating point into stall by increasing the specified exit static pressure ratio from 1.49 to 1.50 . An unsteady rotating stall pattern developed gradually. After 16 rotor revolutions the exit pressure ratio was decreased to 1.10 and the calculations were run another 14 revolutions to simulate stall recovery to a high flow point. Figure 13 shows the locus of the unsteady operating points on the static-to-total pressure ratio characteristics. During stall there was a large variation in inlet mass flow but little variation in pressure ratio which is effectively set by the inlet and exit boundary conditions.

Figure 14 (top) shows the unsteady history of the inlet mass flow plotted against rotor revolutions. The increase in exit pressure reached the inlet boundary in about one revolution and the mass flow began to drop. An oscillation developed in the mass flow after several revolutions and became periodic after 10-12 revolutions. The exit pressure was decreased at 16 revolutions and the inlet mass flow began to increase about one revolution later. The oscillations are still evident at 30 revolutions but are decaying asymptotically towards zero. The bottom of Fig. 14 shows unsteady casing pressure traces at the rotor leading edge at 12 evenly spaced circumferential locations. Pressure oscillations grew gradually over about 10 revolutions then decayed slowly after the exit pressure was decreased at 16 revolutions. The four traces in the center are in the distorted flow region and show more variation in the signal. Analysis of the pressure traces shows that there are two stall sells that rotate at $0.94 \Omega$.

Figure 15 shows axial velocity contours on an unwrapped surface near the casing. Flow is from top to bottom, rotation is left to right, and the low total pressure distorted inflow is at the center. The upper figure shows a stable operating point where the distorted inflow is transported slightly in the direction of the rotation. The lower figure shows the flow during rotating stall where two stall cells are evident in the rotor. Since the tip speed is transonic these cells generate upstream-running shocks that produce the large pressure oscillations seen in Fig. 14.

Figure 16 shows entropy contours on an annular surface near the rotor trailing edge. Rotation is counterclockwise. The left figure shows a stable operating point where the high entropy distorted inflow that started upstream at bottom center has been transported a few blade pitches counterclockwise. The right figure shows the flow during rotating stall. Animations have shown that the flow first becomes unsteady at the 4 o'clock position where the rotor leaves the distorted region. The flow remains quite unsteady at that location as two partspan stall cells form and rotate around the annulus.

\section{SUMMARY AND DISCUSSION}

A 3-D unsteady CFD code called CSTALL was developed and used to investigate distortion and stall phenomena in compressors. The code uses a body force formulation that can be calibrated easily from a few steady Navier-Stokes calculations. CSTALL was used in a 2-D throughflow mode to predict operating maps and estimate stall points quickly and to predict the effects of radial distortion. It was used in a 3-D steady mode to predict the effects of circumferential distortion on the operating map. Finally, CSTALL was used in a 3-D unsteady mode to model rotating stall and recovery from stall. The following observations can be made about the code:

- Marble's formulation of body forces for turning and loss [6] provided an elegant framework for deriving body force information from CFD solutions or experimental data. The body forces gave physically realistic spanwise distributions of turning, deviation, and loss, which are important for accurate prediction of tip-critical stall. Marble's formulation was used for stable operating points, but an iterative scheme developed by Stewart [7] for turning the flow to a specified flow angle was found to be useful for stalled operating points.

- Body force data was input at one operating point and was scaled to other operating points using normalized characteristic maps. This procedure gave good predictions of the entire operating line, but other formulations are possible. For example, data could input at many operating points and interpolated directly, or body force unknowns could be correlated with local incidence along the span. These formulations might improve predictions of stall but would complicate the input to the code.

- CSTALL predicted compressor stall without specification of a stalled characteristic. The predicted stall point was at a slightly lower flow than the experiment and a much lower flow than NavierStokes calculations used for calibration. It was found that the predicted stall point was sensitive to the slopes of the normalized characteristic maps used to scale the body force data to other mass flows. These maps were extrapolated linearly into stall, giving the correct trends for loss and deviation but probably not for $\Delta(r v)$. Further calculations will be needed to find the best way to calculate the normalized characteristic maps and to extend them into stall.

- A throttle exit boundary condition was shown to decrease the predicted mass flow at which the compressor stalled. Since that mass flow was low even without the throttle condition, the throttle condition was not used for most cases shown here. It would be interesting to see if this boundary condition can be used to stabilize NavierStokes calculations. 

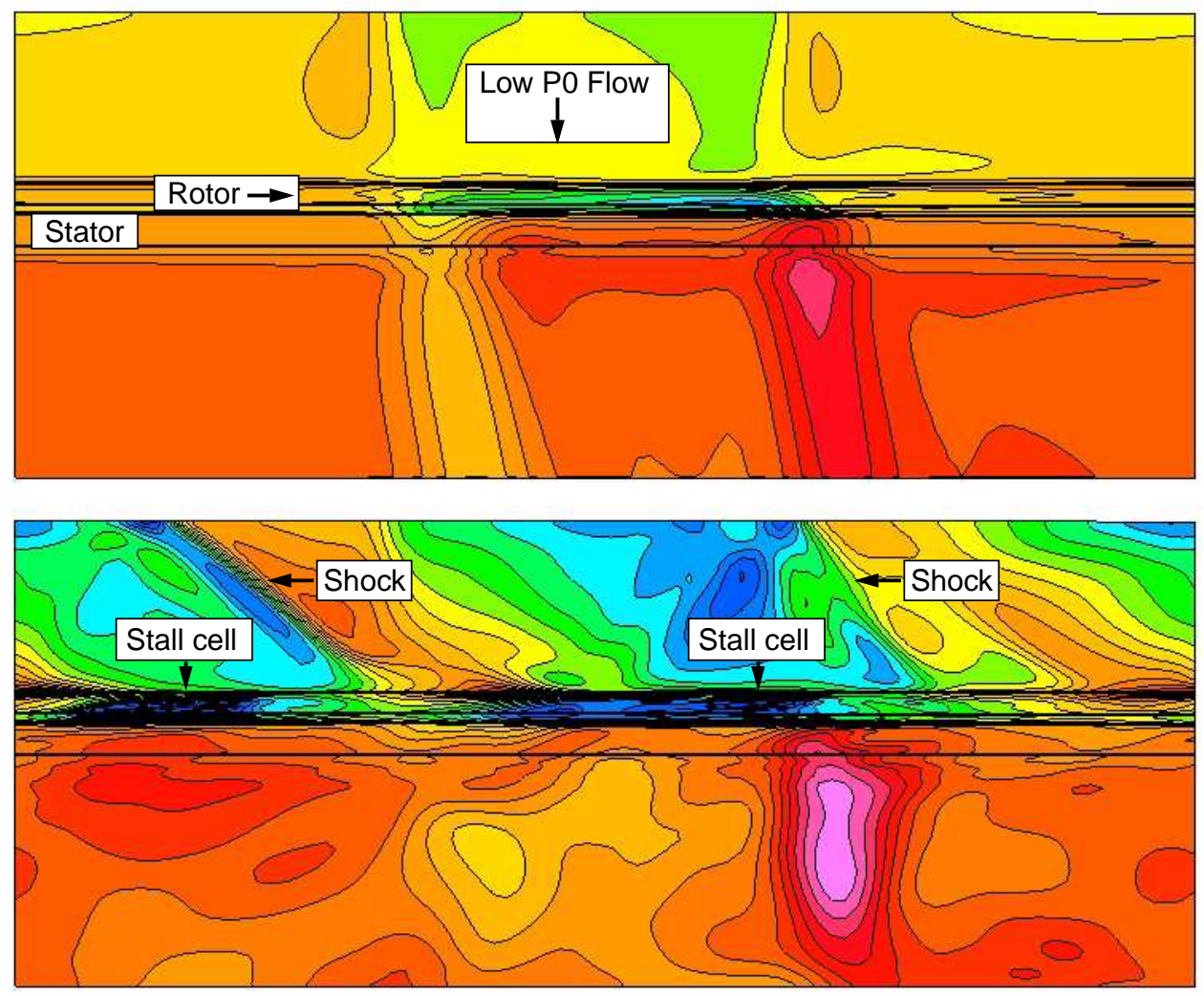

Figure 15 - Axial velocity contours on an unwrapped surface near the tip of stage 35 . Top: Steady flow with circumferential distortion over 120 deg.

Bottom: Stalled flow.
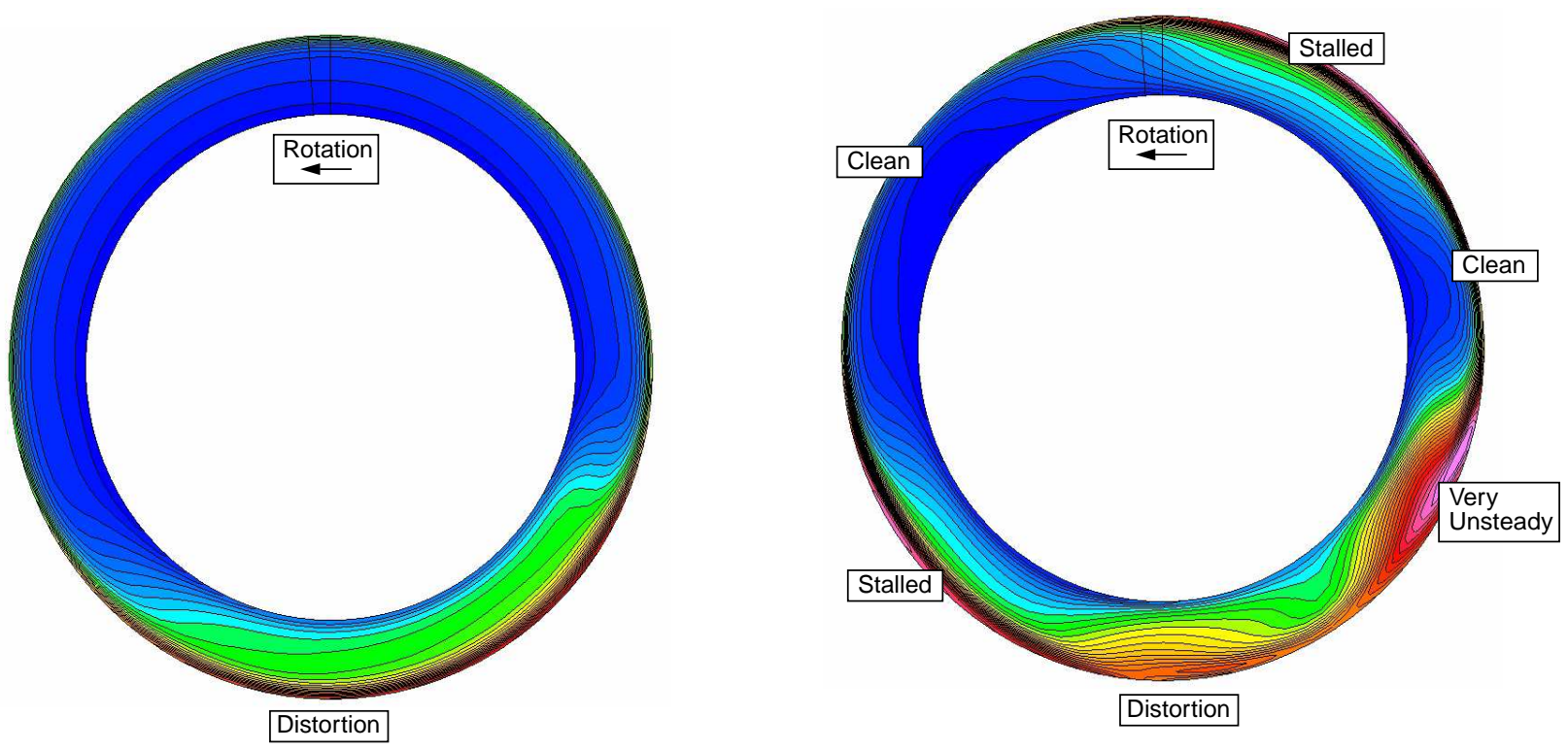

Figure 16 - Entropy contours at the trailing edge of rotor 35. Left: Steady flow with circumferential distortion over 120 deg. Right: Stalled flow. 
- One useful feature of CSTALL was its ability to predict the effects of inlet distortion on a compressor quickly without the need for further Navier-Stokes computations. Radial distortion was analyzed and was shown to reduce the stable flow range of the compressor without affecting the shape of the normalized operating characteristic. Circumferential distortion also reduced the stable flow range of the compressor, but it reduced the static-to-total pressure ratio at all flow rates as well.

- Unsteady calculations showed the ability of the model to predict rotating stall inception and recovery. These calculations used a body force lag equation to model the delayed response of body forces to changes in flow. The model required a time lag parameter that is usually taken to be the blade row throughflow time. Unsteady calculations seemed to be insensitive to changes in this parameter, but further calculations are needed to determine its full effect. It may also be possible to calibrate this parameter using 2-D unsteady Navier-Stokes cascade calculations.

- Further calculations are planned to validate CSTALL predictions of rotating stall and to investigate casing injection flow control for stall prevention and recovery.

\section{REFERENCES}

[1] Pampreen, R. C., 1993, Compressor Surge and Stall, Concepts ETI, Inc., Norwich, VT.

[2] Takata, H. and Nagano, S., 1972, "Nonlinear Analysis of Rotating Stall,” J. Engineering for Power, Oct. 1972, pp. 279-293.

[3] Longley, J. P., 1997, "Calculating the Flowfield of High-Speed Multi-stage Compressors,” ASME Paper 97-GT-468.

[4] Demargne, A. A. J., Longley, J. P., 1997, “Comparisons Between Measured and Calculated Stall Development in Four High-Speed Multi-Stage Compressors," ASME Paper 97-GT-467.

[5] Lindau, J. W., Owen, A. K., 1997, "Nonlinear Quasi-ThreeDimensional Modeling of Rotating Stall and Surge," AIAA Paper 972772.

[6] Marble, F. E., 1964, "Three-Dimensional Flow in Turbomachines," in High Speed Aerodynamics and Jet Propulsion, Vol X, Aerodynamics of Turbines and Compressors, Hawthorne, W. R., ed. Princeton University Press, Princeton, NJ., pp. 83-165.
[7] Stewart, M. E. M., 1995, "Axisymmetric Aerodynamic Numerical Analysis of a Turbofan Engine," ASME Paper 95-GT-338.

[8] Escuret, J. F., Garnier, V., 1994, "Numerical Simulations of Surge and Rotating Stall in Multi-Stage Axial-Flow Compressors," AIAA Paper 94-3202.

[9] Hale, A., and O’Brien, W. O., 1998, "A Three-Dimensional Turbine Engine Analysis Compressor Code (TEACC) For Steady State Inlet Distortion,” J. Turbomachinery, Vol. 120, pp. 422-430.

[10] Hale, A., Davis, M., and Sirbaugh, J., 2004, "A Numerical Simulation Capability for Analysis of Aircraft Inlet-Engine Compatibility," ASME Paper GT-2004-53473.

[11] Gong, Y., Tan, C. S., Gordon, K. A., Greitzer, E. M., 1998, “A Computational Model for Short Wavelength Stall Inception and Development in Multistage Compressors," ASME Paper 98-GT-476.

[12] Gong, Y., 1998, "A Computational Model for Rotating Stall Inception and Inlet Distortions in Multistage Compressors," Ph. D. dissertation, Massachusetts Institute of Technology.

[13] Hsiao, E., Naimi, M., Lewis, J. P., Dalbey, K., Gong, Y., and Tan, C., 2001, "Actuator Duct Model of Turbomachinery Components for Powered-Nacelle Navier-Stokes Calculations," J. Propulsion and Power, Vol. 17, No. 4, pp. 919-927.

[14] Chima, R. V., 1998, "Calculation of Multistage Turbomachinery Using Steady Characteristic Boundary Conditions," AIAA Paper AIAA-98-0968. Also NASA TM-1998-206613.

[15] Chima, R. V., and Liou, M.-S., 2003, "Comparison of the AUSM $^{+}$and H-CUSP Schemes for Turbomachinery Applications," AIAA Paper AIAA-2003-4120. Also NASA TM-2003-212457.

[16] Tweedt, D. L., and Chima, R. V., 1996, "Rapid Numerical Simulation of Viscous Axisymmetric Flow Fields," AIAA Paper AIAA-960449. Also NASA TM-107103.

[17] Reid, L., and Moore, R. D., 1978, "Performance of a SingleStage Axial-Flow Compressor With Rotor and Stator Aspect Ratios of 1.19 and 1.26, Respectively, and With Design Pressure Ratio of 1.82," NASA Technical Paper 1338. 


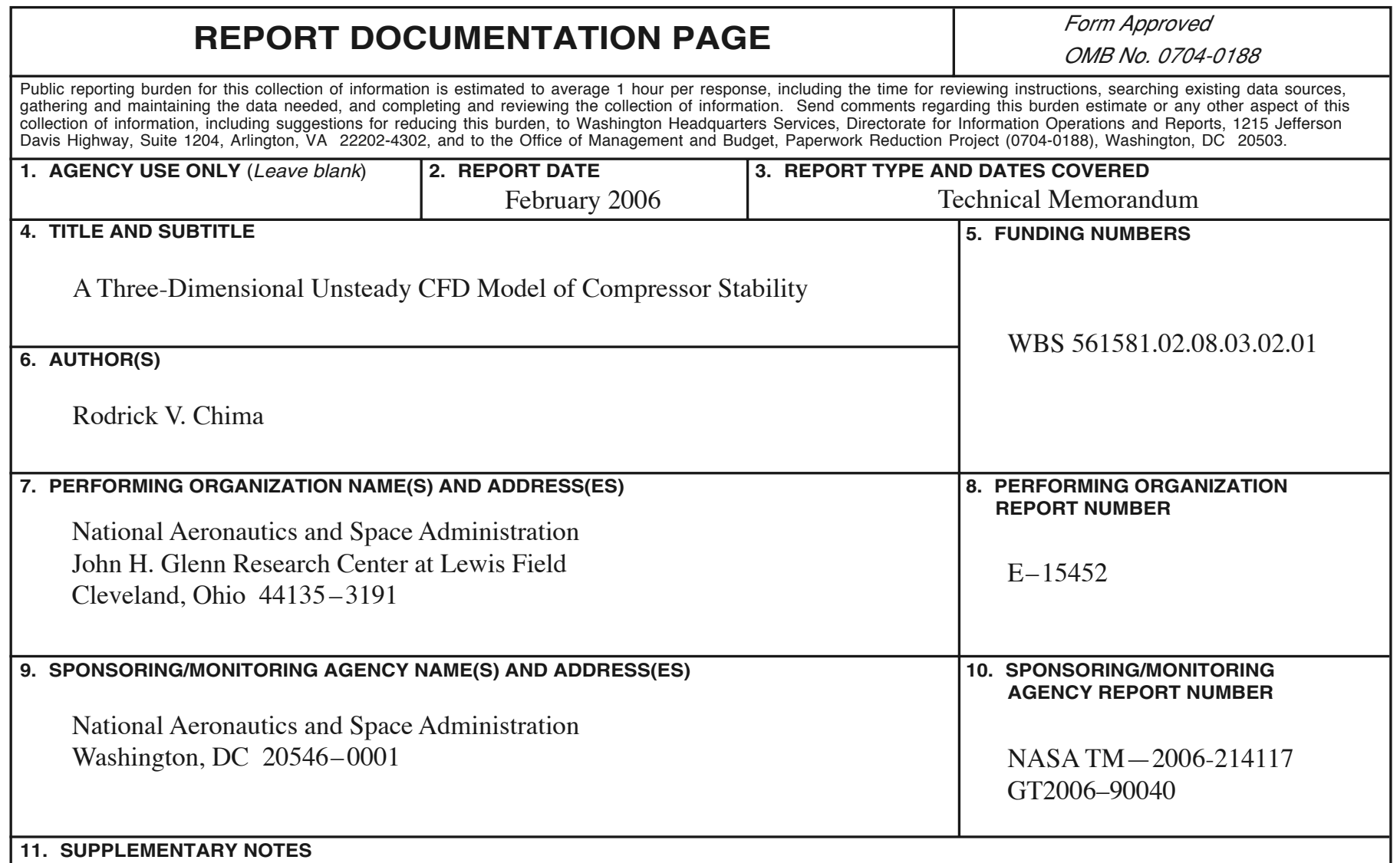

Prepared for Turbo Expo 2006 sponsored by the American Society of Mechanical Engineers, Barcelona, Spain, May 8-11, 2006. Responsible person, Rodrick V. Chima, e-mail: Rodrick.V.Chima@nasa.gov, organization code RTC, 216-433-5919.

12a. DISTRIBUTION/AVAILABILITY STATEMENT

12b. DISTRIBUTION CODE

Unclassified - Unlimited

Subject Category: 07

Available electronically at http://gltrs.grc.nasa.gov

This publication is available from the NASA Center for AeroSpace Information, 301-621-0390.

13. ABSTRACT (Maximum 200 words)

A three-dimensional unsteady CFD code called CSTALL has been developed and used to investigate compressor stability. The code solved the Euler equations through the entire annulus and all blade rows. Blade row turning, losses, and deviation were modeled using body force terms which required input data at stations between blade rows. The input data was calculated using a separate Navier-Stokes turbomachinery analysis code run at one operating point near stall, and was scaled to other operating points using overall characteristic maps. No information about the stalled characteristic was used. CSTALL was run in a 2-D throughflow mode for very fast calculations of operating maps and estimation of stall points. Calculated pressure ratio characteristics for NASA stage 35 agreed well with experimental data, and results with inlet radial distortion showed the expected loss of range. CSTALL was also run in a 3-D mode to investigate inlet circumferential distortion. Calculated operating maps for stage 35 with 120 degree distortion screens showed a loss in range and pressure rise. Unsteady calculations showed rotating stall with two part-span stall cells. The paper describes the body force formulation in detail, examines the computed results, and concludes with observations about the code.

\begin{tabular}{|c|c|c|}
\hline $\begin{array}{l}\text { 14. SUBJECT TERMS } \\
\text { Turbomachinery; Compr } \\
\text { Unsteady flow }\end{array}$ & \multicolumn{2}{|c|}{ 14. SUBJECT TERMS } \\
\hline $\begin{array}{l}\text { 17. SECURITY CLASSIFICATION } \\
\text { OF REPORT } \\
\text { Unclassified }\end{array}$ & $\begin{array}{l}\text { 18. SECURITY CLASSIFICATION } \\
\text { OF THIS PAGE }\end{array}$ & $\begin{array}{l}\text { 19. SECURITY CLASSIFICATION } \\
\text { OF ABSTRACT }\end{array}$ \\
\hline Unclassified & Unclassified & Unclassified \\
\hline
\end{tabular}



